\title{
ESPAÇOS DE PARTICIPAÇÃO MOBILIZADOS PELA GESTÃO ESCOLAR: DESCENTRALIZAÇÃO DE PODER PARA TOMADAS DE DECISÕES NA ESCOLA
}

\author{
Amós Santos Silva ${ }^{1}$ \\ Nayanne Raísa da Silva Alves Batista² \\ Orquídea Maria de Souza Guimarães ${ }^{3}$
}

Resumo: Este artigo busca compreender quais espaços de participação que a gestão escolar organiza para as tomadas de decisões em uma escola pública de Caruaru-PE. Utilizamos a abordagem qualitativa, recorrendo à observação participante e a entrevista semiestruturada envolvendo: gestão escolar; docentes; pais e alunos. Constatamos que a participação de pais, alunos e funcionários nas decisões é praticamente nula gerando uma isenção de responsabilidade por parte destes que delegam à gestão toda tomada de decisão. Concluímos que o planejamento participativo ainda está limitado à gestão da escola e professores.

Palavras-chave: Descentralização de poder. Espaços de Participação. Gestão Escolar.

\section{SPACE FOR PARTICIPATION MOBILIZED BY SCHOOL MANAGEMENT: DECENTRALIZATION OF POWER FOR DECISION MAKING AT SCHOOL}

\begin{abstract}
This article tries to understand which spaces of participation that the school management organizes for the decision making in a public school of Caruaru-PE. We used the qualitative approach, using participant observation and the semistructured interview involving: school management; teachers; parents and students. We found that the participation of parents, students and employees in the decisions is practically null, generating an exemption from responsibility on the part of those who delegate to the management all decision making. We conclude that participatory planning is still limited to the management of the school and teachers.
\end{abstract}

Keywords: Decentralization of Power.Participation Spaces. School management.

${ }^{1}$ Graduando em Pedagogia na Universidade Federal de Pernambuco (UFPE/CAA), bolsista do Programa Institucional de Bolsa de Iniciação à Docência (PIBID) e membro do GEECAMPO (Grupo de Estudo e Pesquisa da Educação do Campo), e do Grupo de pesquisa Formação de Professor e Profissionalização Docente (UFPE/CAA). E-mail: amosantoss10@gmail.com

2 Graduanda em Pedagogia na Universidade Federal de Pernambuco (UFPE/CAA). Email: nayanneraisa@ hotmail.com

3 Doutora em Educação pela Universidade Federal de Pernambuco, professora Adjunta do Centro Acadêmico do Agreste - UFPE, no Núcleo de Formação Docente, atuando no Curso de Graduação em Pedagogia. Participa dos grupos de pesquisa: Discursos e Práticas Educacionais; e Formação de Professor e Profissionalização Docente, ambos da UFPE e registrados no Diretório de Pesquisa do CNPq. E-mail: orquídea.sguimaraes@ufpe.br 


\section{INTRODUÇÃO}

A gestão escolar é uma organização que reúne pessoas que interagem entre si, operando por meio de estruturas e processos organizativos com o objetivo de promover a mobilização e a articulação das condições materiais e humanas necessárias para garantir o avanço dos processos socioeducacionais dos estabelecimentos de ensino e a promoção efetiva da aprendizagem pelos alunos (LIBÂNEO, OLIVEIRA \& TOSCHI, 2003).

Pode-se considerar que o desenvolvimento da gestão ocorre com a participação de todos os membros da comunidade escolar, no sentido de uma ação mais qualificada na construção do conhecimento e na estruturação das relações internas e externas da instituição. Nesse contexto, pensar a escola e suas formas de organização é tarefa complexa e desafiadora, e envolve a compreensão da complexidade na construção dos métodos de planejamento e suas contribuições para a instituição escolar, buscando entender como estão organizados os espaços de participação na instituição escolhida, a fim de apontar as contribuições de sua prática.

Considerando esses fatores, tomamos como questão problema: quais os espaços de participação que a gestão escolar organiza para as tomadas de decisões? Nosso objetivo geral foi analisar tais os espaços, e, para atingi-lo, buscamos: identificar como a gestão entende a participação; caracterizar como são planejadas as atividades para as tomadas de decisões; identificar quem participa das atividades de planejamento e suas respectivas funções.

Consideramos que gestão democrático-participativa ao ser praticada, abre espaços de participação a toda comunidade escolar. E, são nesses espaços que pode ocorrer a participação em busca da prática educativa contextualizada, e a busca coletiva de melhorias da instituição por todos os envolvidos. Entendemos a participação não só como um direito dos membros envolvidos com a instituição escolar em participar planejando e se responsabilizar pela execução e resultados obtidos, pois este comprometimento poderá se tornar propulsor da mudança e da transformação no âmbito escolar.

\section{Gestão Escolar Democrática e Planejamento Participativo-Democrático}

Diversos autores têm estudado o campo da gestão e organização escolar, entre eles Libâneo, Oliveira e Toschi (2003), que abordam o sistema de gestão e organização escolar; 
Botler (2007), que faz referência aos dilemas da gestão democrática escolar no contexto atual; e Ferreira (2013) que sublinha a necessidade de participação para a reestruturação das culturas, políticas e práticas das escolas que, como sistemas abertos, precisam rever suas ações, até então, predominantemente elitistas e excludentes; e Luck (2013), que assinala a importância de constituir um empenho coletivo de todas as pessoas que formam a comunidade escolar para alcançar melhor desempenho dos objetivos educacionais.

O sistema de organização e gestão da escola é o conjunto de ações, recursos, meios e procedimentos que propiciam as condições para alcançar os objetivos da instituição escolar (LIBÂNEO, OLIVEIRA \& TOSCHI, 2003). Para os autores, a gestão é a atividade voltada para o gerenciamento das instituições de ensino, pela qual são mobilizados os processos intencionais e sistemáticos com a finalidade de se chegar a uma decisão e fazê-la funcionar, envolvendo os aspectos gerenciais e técnico-administrativos.

Assim, é importante analisar as formas de organização da gestão para melhor compreendê-la, considerando cultura organizacional que diz respeito aos comportamentos, às formas de relacionamento que surgem espontaneamente entre os membros do grupo. Essa cultura organizacional aparece de duas formas: como cultura instituída e como cultura instituinte.

A cultura instituída refere-se às normas legais, à estrutura organizacional definida pelos órgãos oficiais, às rotinas, à grade curricular, aos horários, às normas disciplinares, etc. A cultura instituinte é aquela que os membros da escola criam, recriam, em suas relações e na vivência cotidiana. (LIBÂNEO, OLIVEIRA \& TOSCHI, 2003, p. 320).

Essa cultura instituinte pode ser modificada pelas pessoas, discutida, avaliada e planejada, o que acentua a importância da busca de objetivos comuns assumidos por todos em uma construção de uma comunidade de aprendizagem a partir da formulação de uma gestão democrático-participativa.

É importante também entender o que seja democracia na gestão da escola. A gestão democrática se consolidou no Brasil a partir da Constituição de 1988, reafirmada na Lei de Diretrizes Bases da Educação Nacional (LDB/1996):

Art. 14. Os sistemas de ensino definirão as normas da gestão democrática do ensino público na educação básica, de acordo com as suas peculiaridades e conforme os 
seguintes princípios: I - participação dos profissionais da educação na elaboração do projeto pedagógico da escola; II - participação das comunidades escolar e local em conselhos escolares ou equivalentes (BRASIL, 1996, p. 08).

Nesse contexto, Botler (2007) diz que a gestão democrática está associada ao fortalecimento da ideia de democratização do trabalho pedagógico, entendida como participação de todos nas decisões e na sua efetivação. É o caminhar da escola contemporânea voltado para uma ação coordenada e coletiva na qual todos os envolvidos no trabalho escolar sintam-se atores desse processo.

Planejar de forma participativa ou democrática, nos remete ao sentido de grupo que idealiza uma ação em conjunto. Mas, todo aquele que planeja uma forma de agir ou de conduzir algo, é concomitantemente responsável pela sua prática e seus resultados, ou seja, “[...] a participação, o diálogo, a discussão coletiva, a autonomia são práticas indispensáveis da gestão democrática, mas o exercício da democracia não significa ausência de responsabilidade" (LIBÂNEO, OLIVEIRA \& TOSHI, 2007, p. 331 e 332).

De acordo com Ferreira (2013) quando falamos em gestão participativa no âmbito da escola pública estamos nos referindo a uma relação entre desiguais onde vamos encontrar uma escola sabidamente desaparelhada. Dessa forma, é preciso que essa escola esteja preparada para enfrentar os desafios de reestruturar as culturas, políticas e práticas, com o intuito de reverter suas ações, até então, predominantemente elitistas, excludentes e centralizadoras do poder. Esteja preparada também para a conscientização da comunidade escolar com a prática da gestão participativa, assim como do próprio exercício da cidadania.

A este respeito, Luck (2013) afirma que o alcance dos objetivos educacionais depende do emprego adequado da energia dinâmica das relações dos diversos atores da comunidade escolar nos processos decisórios da escola de modo a constituir um empenho coletivo em torno de sua realização. É importante salientar que a questão fundamental não é existir uma participação por participação ou participação passiva, o que precisa ocorrer é uma participação efetiva na escola, a qual o coletivo discute e analisa a problemática pedagógica que vivenciam e, a partir dessa análise, determinem caminhos para superar as dificuldades que julgarem mais carentes de atenção e assumam compromisso com a promoção de transformação nas práticas escolares. 
A participação carece estar em seu sentido pleno e engajada, envolvendo o estar presente, o oferecer ideias e opiniões, o analisar de forma interativa as situações, o tomar decisões sobre o encaminhamento de questões com base em análises compartilhadas e envolverse de forma comprometida para a efetivação das tomadas de decisões (LUCK, 2013). Em suma, é uma participação que corresponde a uma atuação conjunta superadora das expressões de alienação e passividade, autoritarismo e centralização, intermediada por cobrança e controle.

Além disso, a clareza de objetivos orientados por princípios e valores como ética, solidariedade, equidade, compromisso, bem como, a compreensão de suas implicações quanto à ação do desenvolvimento do ser humano como ser social, com espírito de coletividade, de envolvimento da família e da comunidade no processo político-pedagógico escolar, da maior integração entre currículo escolar/aprendizagem dos alunos e a realidade e a criação de um ambiente formador de cidadania e habilidades participativas, todos estes fatores tornam a participação mais efetiva e competente (LUCK, 2013).

Nesse contexto, nem a gestão e nem os demais atores do convívio escolar participantes do processo de planejamento estão isentos de responsabilidade devido ao comprometimento social necessário nos processos democráticos, em especial nos que dizem respeito ao ato de formar e educar pessoas. Afinal dentre os princípios de planejamento participativo-democrático estão, além da autonomia referente ao planejar e responsabilizar-se pelo que se planejou, autonomia da escola, execução do que se planejou, formação continuada para o desenvolvimento pessoal e profissional dos membros da escola, democratização das informações e avaliação compartilhada.

Para falar de planejamento participativo-democrático e de autonomia se faz necessário entender o sentido de instituição autônoma, que é a " [...] instituição que tem poder de decisão sobre seus objetivos e sobre suas formas de organização, que se mantém relativamente independente do poder central e administra livremente seus recursos financeiros" (LIBÂNEO; OLIVEIRA \& TOSHI, 2007, p. 333).

Segundo Fischer e Guimarães (2013) a gestão autônoma das escolas requer uma participação mais ativa do corpo docente e das famílias dos alunos nos processos decisórios em que as decisões são tomadas de forma colegiada pelos atores envolvidos, direta ou 


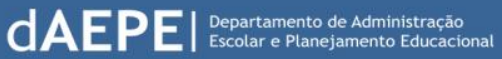

indiretamente. A gestão autônoma só pode existir se houver uma transferência de poder de decisão para o âmbito da escola, inclusive de recursos.

Devido à escola pública não agir isoladamente e os recursos não serem originados da própria escola, mas sim advindo de estâncias como município ou estado seu planejamento se ver obrigado à adequar-se e aplicar entre outras coisas as diretrizes gerais que recebe desses níveis superiores de administração. Portanto, não afirmamos necessariamente que o planejamento não seja participativo, porém, é perceptível e quase que "comum” que a participação aconteça de forma induzida a fim de corresponder as expectativas destas estâncias. Assim, os discursos a respeito da existência de uma escola pública autônoma não ocorrem na prática, uma vez que a escola não tem total autonomia sobre suas decisões.

\section{PERCURSO METODOLÓGICO}

A pesquisa recorreu à abordagem qualitativa que, segundo André (2008), é um estudo farto de dados descritivos, aberto e flexível, desenvolvido numa situação natural e que focaliza a realidade de forma complexa e contextualizada. Realizamos a pesquisa em uma escola municipal de Caruaru-PE, que atende alunos nos três turnos, selecionada em função de se caracterizar como campo de estágio curricular do Curso de Pedagogia CAA/UFPE.

Essa pesquisa envolveu nove participantes: 03 funcionários da gestão (gestora, secretária, coordenadora), 02 professores (D1, D2), 02 alunos (A1, A2) e 02 pais de alunos (P1, P2), entendendo que só com a participação de todos os que compõem o convívio escolar é que se pode compreender a participação pela visão da escola, a caracterização das atividades e as respectivas funções dos atores que participam do planejamento participativo.

Como instrumento de coleta de dados utilizamos a observação participante que parte do princípio de que o pesquisador tem sempre um grau de interação com a situação estudada, afetando-a e sendo por ela afetado. No entanto, o referido não pode intervir no seu objeto de estudo. Utilizamos também a entrevista do tipo semiestruturada por neste tipo de entrevista, o entrevistador tem um conjunto de questões predefinidas, mas mantém liberdade para colocar outras cujo interesse surja no decorrer de seu desenvolvimento. Esse procedimento ofereceu informações que complementaram as observações realizadas.

Utilizamos a técnica de Análise de Conteúdo para tratarmos com os dados coletados, parafraseando Gil (2008), a mesma foi desenvolvida em três fases principais: a pré-análise; a 


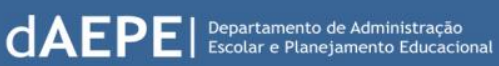

exploração do material; e o tratamento dos dados, inferência e interpretação. Portanto, em nossa pesquisa a análise dos dados coletados foi sistematizada e realizada conforme as categorias analíticas desveladas a partir da inferência e interpretação dos dados com os objetivos do trabalho.

\section{RESULTADOS}

\section{Gestão escolar e Participação}

A gestão da escola é a responsável pela articulação de todos os segmentos da escola que vão assegurar a aprendizagem dos alunos, é a responsável pelo funcionamento da escola. “[...] é a gestão que organiza a escola, que busca o bom funcionamento das coisas, tudo está sob a nossa responsabilidade" (ENTREVISTA COM A GESTORA, Junho de 2017). Conforme Luck (2013):

Ressalta-se que a gestão educacional, em caráter amplo e abrangente, do sistema de ensino, e a gestão escolar, referente à escola, constituem-se em área estrutural de ação na determinação da dinâmica e da qualidade do ensino. Isso porque é pela gestão que se estabelece unidade, direcionamento, ímpeto, consistência e coerência à ação educacional [...] Em vista disso, o necessário reforço que se dá à gestão visa, em última instância, a melhoria das ações e processos educacionais, voltados para a melhoria da aprendizagem dos alunos e sua formação [...] Em suma, aperfeiçoa-se e qualifica-se a gestão para maximizar as oportunidades de formação e aprendizagem dos alunos (LUCK, 2013, p. 17-18).

Além dessa responsabilidade, a gestão se encarrega de todos os assuntos pertinentes à escola, desde a justificativa das faltas doas alunos até a fiscalização da merenda escolar.

Diante dessa amplitude de funções, a gestora fala da dificuldade que se tem quando não há o empenho por parte de todos que compõem a comunidade escolar: "O gestor sozinho não consegue assegurar o funcionamento de toda a escola. E, um problema frequente é a falta de participação da comunidade escolar juntamente com a equipe gestora, o que dificulta o trabalho técnico-pedagógico" (ENTREVISTA COM A GESTORA, Julho de 2017). Dessa forma, a gestão entende que a participação da comunidade escolar como um todo é fundamental para o funcionamento da escola. Segunda a diretora, “[...] quando todos os sujeitos estão engajados na realização das atividades escolares conseguimos um maior aproveitamento das atividades planejadas" (ENTREVITA COM A GESTORA, Julho de 2017).

Quanto à participação, percebemos que o planejamento envolve diretores, coordenadores e professores que buscam entrar em um consenso em reuniões de planejamento. $\mathrm{O}$ 


\section{REVISTA DE ADMINISTRAÇÃO EDUCACIONAL}

comprometimento observado com relação ao que se planeja também é distribuído entre eles. Porém, a participação fica restrita à gestão e docentes, sem envolver estudantes, pais, funcionários.

A participação de pais de alunos fica quase isenta, uma vez que as reuniões são restritas a comunicação do "código de conduta" que deve ser seguido pelos alunos e divulgação de notas nas chamadas "reuniões pedagógicas" que acontecem a cada bimestre. Estas reuniões possuem caráter apenas informativo e de cobrança. Segundo um dos nossos sujeitos P1, afirmou durante a entrevista que: “[...] as reuniões são feitas pra dizer a nota, ou pra falar que meu filho não tá se comportando" (ENTREVISTA, Julho de 2017).

As reuniões para a construção do projeto político pedagógico contam apenas com a presença de professores e da gestão. Deixando de fora qualquer contribuição advinda da comunidade ou mesmo dos alunos. Assim, entendemos que apesar da gestão considerar fundamental a participação de toda a comunidade escolar nos processos de tomadas de decisões, o planejamento participativo fica restrito aos discursos da escola e que alunos e pais, em sua maioria, não se sentem incomodados por não participarem das decisões da escola. Um pai quando questionado sobre o que ele pensava das decisões da escola, responde (P2): “A escola é muito boa não precisa que eu esteja me metendo, não acho que seja necessário eu participar, se a escola não sabe o que é melhor eu é que não vou saber" (ENTREVISTA, Julho de 2017).

Essa isenção de participação acaba gerando uma isenção também da responsabilidade, transferindo toda responsabilidade de execução e resultados para o ambiente escolar. Impossibilitando também de aproximar a escola da realidade na qual o aluno vive suas necessidades e preferências, suas habilidades e restrições.

\section{Gestão e o Planejamento das Atividades}

O planejamento das atividades foi um dos aspectos pesquisado nas escolas. Evidenciou-se por meio da entrevista, o qual a diretora fala sobre o planejamento das atividades escolares, que o diálogo contribui muito para a melhoria do planejamento, revisão do processo, aperfeiçoamento da metodologia e introdução de novos recursos pedagógicos, visando o aperfeiçoamento global do processo de ensino-aprendizagem. 
As atividades são planejadas de acordo com as necessidades. Procuramos resolver as situações mais urgentes. Em relação às reuniões, temos um calendário estabelecido pela secretária da educação e algumas quando tem necessidade marcamos. As festividades são programadas de acordo com as manifestações culturais presentes em nossa cidade e as datas são adaptadas ao calendário letivo. Esses dias festivos são decididos em conjunto com o corpo pedagógico. Em cada semestre a secretária de educação solicita um dia para o acontecimento de palestras e eventos com temas atuais da sociedade como violência contra a mulher, bullying, saúde bucal entre outros. Temos também em cada semestre uma feira de ciências que os alunos, por turmas, expõem de forma lúdica e prazerosa os conteúdos aprendidos no semestre em uma disciplina de sua escolha. (FRAGMENTO DA ENTREVISTA COM A GESTORA, Julho de 2017).

Nesta direção, segundo Libâneo (2001):

Uma importante característica do planejamento é o seu caráter processual. $\mathrm{O}$ ato de planejar não se reduz à elaboração dos planos de trabalho, mas a uma atividade permanente de reflexão e ação. O planejamento é um processo contínuo de conhecimento e análise da realidade escolar em suas condições concretas, de busca de alternativas para a solução de problemas e de tomada de decisões, possibilitando a revisão dos planos e projetos, a correção no mundo das ações. (LIBÂNEO, 2001, p. 124).

Dessa forma, o processo de planejamento não consiste em elaborar um conjunto de metas de ação a serem posteriormente concretizadas. Não se caracteriza apenas por um conjunto de ações que são previamente estabelecidas no começo do ano e serão realizadas durante todo o ano letivo sem nenhuma alteração no decorrer da realização das atividades. Todavia, o planejamento totaliza um processo cíclico de reflexão e de ação, o qual está sempre integrado na reflexão como uma análise da ação e na ação como concretização da reflexão. Esse movimento cíclico resulta num processo de permanente análise e renovação do planejamento.

Nesse sentido, para o pleno funcionamento do planejamento das atividades, é necessário que se tenha uma gestão escolar com participação de todos os envolvidos na comunidade escolar para a tomada de decisões e na elaboração de metas e estratégias de ação. O planejamento tem a função de analisar a realidade escolar, identificando as dificuldades existentes e a sua causa, definir os objetivos e metas que compatibilizam com o sistema escolar, na determinação de atividades compatíveis com os recursos materiais e humanos disponíveis na escola. A participação, além de aprimorar a gestão, agrega a responsabilidade e compromisso coletivo com os objetivos comuns definidos.

No que se refere à gestão, a equipe gestora manifesta o sentido do planejamento realizado em conjunto com a comunidade. Essa equipe entende que o planejamento deve ser expandido no sentido de envolver toda a comunidade escolar, pois as ações são desenvolvidas 


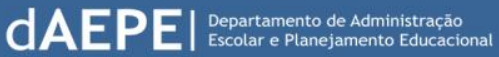

com a intenção de alcançar as mudanças desejadas. Os pontos positivos e a limitações próprias da dinâmica escolar precisam ser periodicamente avaliados para aprimorar as ações.

Em relação ao trabalho docente, a escola recebe um material padronizado que foi enviado pela Secretária de Educação, sendo apenas necessária a sua aplicação pelo professor. Observou-se que os professores são orientados a planejar suas atividades em conformidade com esse material e as diretrizes do Projeto Político Pedagógico (PPP) da escola. Os professores têm liberdade para trabalhar outros conteúdos além do material que é mandado pela secretária da educação e atividades para ir além da apostila. Cada professor conhecendo os alunos com os quais trabalha, tem de saber o que vai ensinar e como fará isso ao longo do trabalho educativo.

Antes da professora ir pra sala e começar a atividade, vimos que ela analisou o PPP da escola. A professora do $4^{\circ}$ "A" trabalhou raciocínio lógico com a turma. Ela utilizou o jogo de damas para deixar a aula mais lúdica. As crianças se divertiram muito e depois pegaram o livro para resolver algumas questões. Compreendemos que ela fez uma ponte entre usar o material do livro, o lúdico e o PPP durante a sua aula. (FRAGMENTO DO DIÁRIO DE CAMPO, 25/05/17).

Através do PPP, os professores constroem a mediação entre as exigências específicas de suas disciplinas e a ação conjunta de toda a escola. Entende-se que para um bom planejamento, deve ser considerada a qualidade de aprendizagem de todos os discentes e realizar o diagnóstico da produção dos alunos com frequência.

Durante nossa permanência no campo, podemos ver esse planejamento de atividades na prática. Presenciamos a festividade do Dia das Mães e a festa do São João.

O expediente começou às $8 \mathrm{~h}$, já que hoje é a festividade do Dia das Mães. Os funcionários da gestão receberam as mães que estavam acompanhadas dos seus filhos. Nessa hora percebemos a quantidade de crianças que estavam lá com as avós, algumas até mesmo com os pais e outras com o semblante bem triste que começaram a chorar na hora da sua apresentação por não estar com a sua mãe. Depois da recepção, os alunos seguiram para o lado direito da quadra e as mães para o lado esquerdo. Em seguida, começaram as apresentações chamadas por turmas. Após terminada as apresentações, foi servido um lanche que era bolo, cachorro quente, guaraná e suco; durante o lanche foram feitos alguns sorteios de lembrancinhas para as mães (FRAGMENTO DO DIÁRIO DE CAMPO, 12/05/17).

A diretora nos relatou na semana seguinte que o quantitativo de mães que compareceram foi muito abaixo do esperado. Essa é uma das dificuldades que a gestão encontra para a realização das atividades, uma resistência dos pais em participar de momentos de confraternização. Durante a preparação da festividade de São João podemos perceber o empenho das professoras. Elas ensaiavam com as crianças e confeccionavam os enfeites que 
elas iriam utilizar no dia, além de fazer os cordéis paras as apresentações. As crianças também correspondiam a esse empenho, prestavam atenção nas ordens dadas pelas professoras, se engajavam nos ensaios e ajudavam na confecção dos enfeites.

Percebemos também que as reuniões são elaboradas e seguem o calendário enviado pela Secretaria de Educação e, além dessas, algumas reuniões são levantadas pela equipe gestora conforme os problemas e as necessidades observadas pela diretora. O diálogo que ocorre nessas reuniões abre espaço para que as opiniões colocadas pelos participantes sejam avaliadas e efetivadas na escola propiciando um meio para a verificação do alcance efetivo das metas e objetivos estabelecidos pela escola. A abertura do diálogo em equipe resulta no desenvolvimento de uma metodologia comum de trabalho que motiva a aprendizagem dos alunos.

Quando consta na pauta de reunião o planejamento escolar, o gestor faz a mediação entre as questões a serem discutidas em equipe. Os principais assuntos referentes à dinâmica escolar precisam ser informados e discutidos em conjunto com a finalidade de desenvolver o sentimento de responsabilidade comum a todos no planejamento escolar.

Conclui-se, a partir dos dados coletados, que a orientação para o planejamento das atividades pedagógicas envolve toda a instituição e são planejadas e orientadas nessas reuniões, com a equipe gestora, docentes e demais funcionários da escola. As atividades para as tomadas de decisões são supervisionadas pela respectiva coordenação, seja através de reuniões de planejamento, seja através de momentos pessoais ou por áreas. O processo e o exercício do planejamento são uma antecipação da prática, ou seja, planejar é predizer e programar as ações e os resultados desejados, possibilitando a tomada de decisões por parte de todos que formam a comunidade escolar.

\section{Os Sujeitos e suas "funções" Participativas}

De acordo com Botler (2007) é preciso que se defenda um novo estilo de caminhar da escola voltada para uma ação coordenada, coletiva, na qual todos os envolvidos no trabalho escolar sintam-se atores desse processo. A escola é formada por sujeitos pensantes que lutam por uma sociedade justa, procurando promover ações participativas e atividades que visem o envolvimento e o comprometimento das pessoas. Assim, cada membro e cada setor da estrutura escolar necessitam assumir seu papel para construir uma escola democrática e participativa. 
Durante nossa observação em campo, podemos observar os sujeitos que participam do planejamento das atividades. No decorrer da observação, percebemos que os sujeitos que participam direta ou indiretamente são pais, alunos, professores e funcionários da escola. Através da entrevista com a gestora foi possível saber quais os sujeitos que participam e quais as suas respectivas funções nas atividades da instituição.

Os pais podem participar através dos plantões pedagógicos que seria para acompanhar o
desempenho da escola e através das reuniões de pais e mestres para acompanhar o
desempenho, a aprendizagem dos seus filhos, mas a escola mantém uma comunicação
ativa com os pais através do uso da agenda escolar. Essas reuniões ocorrem ao final de
cada bimestre. [...] Temos uma reunião mensal com os funcionários da escola para tratar
assuntos referentes ao pleno funcionamento da escola, por exemplo: prestação de contas,
o horário de chegada e saída dos alunos e dos funcionários, fardamento, merenda, uso de
celular na aula entre outros assuntos que surgem no decorrer do ano letivo. [...] Os
professores participam dessas reuniões mensais e, além disso, participam de uma reunião
do corpo docente que ocorre quinzenalmente para tratar de assuntos referentes a sala de
aula, os alunos que estão faltando muito, com problemas de aprendizagem ou que estão
dando muito trabalho as professoras (FRAGMENTO DA ENTREVISTA COM A
GESTÃO, Julho de 2017).

O estudante age no processo produtivo escolar com vistas à consecução de um fim educativo, sendo produtor e coprodutor junto a outras pessoas, além de "objeto de trabalho" (BOTLER, 2007). No decorrer da nossa pesquisa na escola, não foi possível ver nenhuma atividade em que o aluno interferisse nas decisões a respeito da escola. O que foi observado eram os alunos realizando as atividades com a professora para a preparação da festa do Dia das Mães e da Festa Junina.

A integração família e escola ainda ficaram muito aquém das propostas teorizadas sobre o assunto. Existe uma dificuldade muito grande visto que, segundo dados coletados por meio da observação e da entrevista, os encontros entre a família e a gestão são reuniões por bimestre para saber sobre a nota, o desenvolvimento do aluno(a) na aula. P1 nos relata que: “[ ...] Temos reuniões por bimestre para saber do desenvolvimento das crianças. É nessas reuniões que sabemos onde precisamos intervir na educação dos nossos meninos (alunos em geral)".

Não podemos observar nenhuma reunião de pais e mestres, mas podemos observar a relação respeitosa que existe entre os pais e os funcionários da escola. Sempre que um pai ou mãe chega à escola são bem tratados e tinham seus problemas resolvidos parcial ou totalmente (FRAGMENTO DO DIÁRIO DE CAMPO, 13/06/17). 
Nas observações, foi apreendido que os pais podem participar através dos plantões pedagógicos que seria para acompanhar o desempenho da escola e através das reuniões de pais e mestres para acompanhar o desempenho, a aprendizagem dos seus filhos. Essas reuniões ocorrem ao final de cada bimestre. Na entrevista com a docente D1, ela nos relata que "[...] ao final de cada mês nos reunimos para falar sobre o pleno funcionamento da escola e assim facilitar o nosso trabalho escolar. E quinzenalmente temos reuniões para tratar de assuntos da sala de aula" (ENTREVISTA D1, Julho de 2017).

$\mathrm{O}$ expediente terminou às $11 \mathrm{~h} 30$ min e ficamos para observar a reunião quinzenal que iria ocorrer com as professoras e a gestão. Trataram de assuntos referentes a sala de aula. Um aluno está doente a mais de 30 dias com pneumonia e as professoras estão preocupadas com o seu ano letivo já que antes de adoecer, a criança apresentava déficit de atenção e aprendizagem. Houve sugestões de todas ambas as partes e chegaram a uma decisão. Iriam fazer algumas atividades complementares para serem enviadas para a criança fazer em casa nos momentos em que estivesse se sentindo melhor. A mãe da criança também estava presente nessa reunião em particular e aproveitou a oportunidade para agradecer o apoio da escola e levar o atestado médico. Depois que esse assunto foi resolvido a mãe foi embora e a reunião continuou. As professoras começaram a dar sugestões sobre a festa junina. Fizeram os encaminhamentos e a reunião foi encerrada (FRAGMENTO DO DIÁRIO DE CAMPO, 09/06/17).

Durante a reunião percebemos a interação que há entre a gestão e o corpo docente. As sugestões dadas pelas professoras foram acatadas pela gestão e vimos à materialidade desse planejamento no dia da festividade junina. Os professores têm função de participar dessas reuniões mensais e, além disso, participam de uma reunião do corpo docente que ocorre quinzenalmente para tratar de assuntos referentes à sala de aula, os alunos que estão faltando muito, com problemas de aprendizagem ou que estão dando muito trabalho as professoras.

Neste sentido, Libâneo, Oliveira e Toschi (2005) afirmam que o corpo docente é o conjunto dos professores em exercício na escola, cuja função básica consiste em contribuir para o objetivo prioritário da instituição, o processo de ensino e aprendizagem e completa ao relatar que à docência têm a responsabilidade de participar da elaboração do plano escolar e do projeto pedagógico, da realização das atividades escolares, das decisões do conselho de escola, de classe ou de série, das reuniões com os pais e das demais atividades cívicas, culturais e recreativas da comunidade.

Os funcionários da escola são responsáveis pelo bom funcionamento escolar, pelos processos " [...] intencionais e sistemáticos com a finalidade de se chegar a uma decisão e de fazer a decisão funcionar envolvendo os aspectos gerenciais e técnico-administrativos" 


\section{REVISTA DE ADMINISTRAÇÃO EDUCACIONAL}

(BOTLER, 2007, p. 48). Todos precisam prestar contas, fiscalizar o horário de chegada e saída dos alunos e dos funcionários, observar o fardamento, a merenda além desses aspectos:

É importante levar em consideração os comportamentos, as ações e as formas de relacionamento entre os indivíduos que fazem parte da escola, lembrando que a cultura de cada indivíduo influencia e contribui para a cultura organizacional da qual o indivíduo participa (BOTLER, 2007, p. 49).

Conforme reitera Libâneo, Oliveira e Toschi (2005) tais tarefas administrativas têm a função de fornecer o apoio necessário ao trabalho docente, este por sua vez abrange o trabalho de secretaria, serviços gerais, atividades de limpeza e de conservação do prédio, provimento e conservação dos recursos materiais, administração dos espaços físicos e das dependências. Incluem também a gestão de recursos financeiros. O trabalho do diretor, do vice-diretor, do supervisor, da coordenação, da secretária, ou seja, da equipe gestora é coordenar, organizar e gerenciar todas as atividades da escola, auxiliado pelos demais elementos do corpo técnicoadministrativo.

É de fundamental importância que todos os que estão comprometidos com a escola saibam suas funções, seus direitos e deveres para que se consiga uma visão de que todos estão juntos para promover o desenvolvimento do "ser humano como ser social (cidadão)" e a transformação da escola como unidade social dinâmica e aberta à comunidade e não seja, como muitas vezes é hoje considerada, uma responsabilidade exclusiva de governo e da escola. É necessário que se desenvolva o sentimento de "[...] comunitarismo e o espírito de coletividade na escola, caracterizados pela responsabilidade social conjunta, de modo que esta se torne ambiente de expressão de cidadania por parte de seus profissionais e de aprendizagem social e efetiva e de cidadania, por seus alunos" (LUCK, 2013, p. 52-53).

\section{CONSIDERAÇÕES FINAIS}

Compreendemos a gestão escolar como uma estrutura de articulação na qual todos os componentes da organização escolar se integram de forma recíproca. Entendemos que é papel do gestor proporcionar espaço para a participação de todos os setores da escola no âmbito das decisões no processo pedagógico e administrativo. Desse modo, os resultados que serão obtidos favorecerão o conhecimento interdisciplinar e a qualidade da educação. 


\section{REVISTA DE ADMINISTRAÇÃO EDUCACIONAL}

Pensar a Gestão Escolar é lutar contra mecanismos neoliberais que permeiam os meios de comunicação social para superar o individualismo e formar no interior da escola uma cultura de participação. Os gestores escolares têm o desafio de democratizar os saberes e as práticas dentro da escola, procurando envolver todos os sujeitos a fim de que cada um assuma seu papel em prol de uma escola mais participativa.

Ao observar os resultados obtidos por meio da análise dos dados, percebemos que a gestão tem um papel fundamental na organização da instituição escolar. Contudo, para se alcançar essa organização com maior aproveitamento das atividades, é necessário que se tenha a participação de todos os sujeitos da comunidade escolar. Concluímos então que o processo de planejamento é baseado apenas no olhar da docência e da gestão, porém usa de discursos demagogos de participação. Participação essa que não foi identificada na prática do campo escolhido.

A participação é a nosso ver a melhor maneira de aproximar a escola dos alunos e de seus familiares, levando em consideração que é mais fácil se preocupar com o que planejamos, do que com o que planejaram, ou seja, planejar junto fará com que o objetivo seja comum a todos. A busca pela execução e resultados, será uma busca coletiva. Entendemos ainda que não é uma busca impossível, mas que sua realização depende do trabalho árduo em desmistificar o conceito de participação que a maioria dos funcionários possui e do esclarecimento da temática e aproximação escolar dos demais atores do âmbito escolar.

Além disso, podemos constatar uma relação harmoniosa entre os funcionários da gestão e o corpo docente que juntos tomam as decisões acerca do planejamento da escola. A escola organiza reuniões com os docentes para ouvir a opinião deles acerca dos assuntos que permeiam a instituição e entendemos que a maioria dessas opiniões são materializadas. Vimos que o trabalho docente é norteado pelo Projeto Político Pedagógico (PPP) da escola, mas o professor tem autonomia para além dos recursos enviados pela Secretária da Educação, utilizar outros recursos didáticos no decorrer da sua aula.

Concluímos, confirmando o nosso pressuposto quando relatamos que a gestão ao abrir espaço para a participação de todos que formam a comunidade escolar terá a comunidade em que a escola está inserida mais consciente, em busca da prática educativa e de melhorias para instituição. Favorecendo o maior aproveitamento do processo de ensino-aprendizagem de todos 


\section{REVISTA DE ADMINISTRAÇÃO EDUCACIONAL}

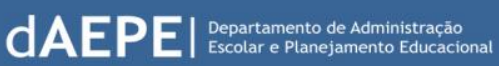

os que estão de alguma forma relacionada à escola. Quando todos participam os resultados obtidos tendem a ser grandiosos.

\section{REFERENCIAS}

ANDRÉ, Marli Eliza D. A. de. Etnografia da prática escolar. Papirus Editora. 2008.

BOBBIO, Norberto. O Futuro da Democracia: uma defesa das regras do jogo. Trad. Marco Aurélio Nogueira. 6 ${ }^{a}$ Edição. Editora Paz e Terra. Rio de Janeiro. 1997

BOTLER, Alice Happ. Organização, Financiamento e Gestão Escolar: subsídios para a formação do professor. Editora Universitária UFPE. Recife. 2007.

BRASIL. Lei de Diretrizes e Bases da Educação Nacional. Lei no 9.394 de 20 de dezembro de 1996 - 5 ed. - Brasília: Câmara dos Deputados, Coordenação Edições Câmara, 2010. Disponível em: $\lfloor$ https://www.puc-campinas.edu.br/midia/arquivos/2013/abr/proavi---lei-n-93941996.pdf >.

Acesso em: 04/2017.

BRASIL. Secretaria de Educação - SEB. Programa Nacional de Fortalecimento dos Conselhos Escolares: Conselho escolar, gestão democrática da educação e eleição de gestores. 2004.

FERREIRA, Naura S. Capareto. Gestão democrática da educação: atuais tendências, novos desafios. $8^{\text {a }}$ Ed. Editora Cortez. São Paulo. 2013

FISCHER, S. D.; GUIMARÃES, M. C. L.. A construção da gestão autônoma das escolas públicas brasileiras: um estudo nas escolas de ensino fundamental em Santa Catarina. In: Revista Brasileira de Política e Administração da Educação - Periódico científico editado pela ANPAE, v. 29, n. 1 (2013).

LIBÂNEO, José Carlos; OLIVEIRA, João Ferreira de; TOSHI, Mirza Seabra. Educação escolar: políticas, estrutura e organização. $2^{a}$ Ed. Editora Cortez. São Paulo. 2005.

LUCK, Heloísa. A gestão participativa na escola. 11 ${ }^{\text {a }}$ Ed. Editora Vozes. Rio de Janeiro. 2013. 